\title{
RETÓRICA, A CIÊNCIA \\ DA EDUCAÇÃO
}

Tarso B. Mazzotti ${ }^{1}$

\section{Resumo}

O autor examina o problema da cientificidade da Pedagogia (Educação), que é o mesmo de qualquer ciência: o da validade da indução, cuja solução é admitir a eficácia das regras do modus tollens. Estas regras não solucionam por inteiro o problema da validaçáo da inferência indutiva, pois as premissas de seu silogismo sustentam-se em modelos, os quais são objetos de disputas resolvidas por negociações de seus significados. Essas negociaçôes ocorrem nas situaçôes sociais retórica e dialética, das quais resultam os conhecimentos organizados para fins de exposição (didascália). Para o autor, as técnicas retóricas, dialéticas e lógicas (analíticas) constituem, em conjunto, as condiçōes necessárias, ainda que insuficientes, para a produçấo e exposição de conhecimentos científicos. Recorda que há dois tipos de ciências: as construtivas e as reconstrutivas. As construtivas operam com signos auto referentes e têm por objeto as operaçóes sobre conjunto de signos (lógicas e matemáticas). Enquanto as reconstrutivas partem de comparaçôes para constituírem algum modelo, ou metáfora, que permita apreender e explicar o que elas póem como objeto. $\mathrm{O}$ autor inclui a Retórica dentre as ciências reconstrutivas e sustenta que esta examina os limites do axioma modal comum às artes retóricas, educativas e as denominadas poéticas: é possível modificar as crenças, valores e atitudes. $\mathrm{O}$ qual é o objeto comum daquelas artes, logo a ciência constituída para dele tratar, a Retórica, também é a ciência das práticas educativas.

Palavras-chave: Pedagogia; Ciências da Educação; Retórica; Epistemologia das Ciências da Educação.

1 Tarso B. Mazzotti é professor aposentado da UFRJ, trabalhando atualmente como professor do Programa de Pós Graduação em Educaçáo da Universidade Estácio de Sá do Rio de Janeiro. 


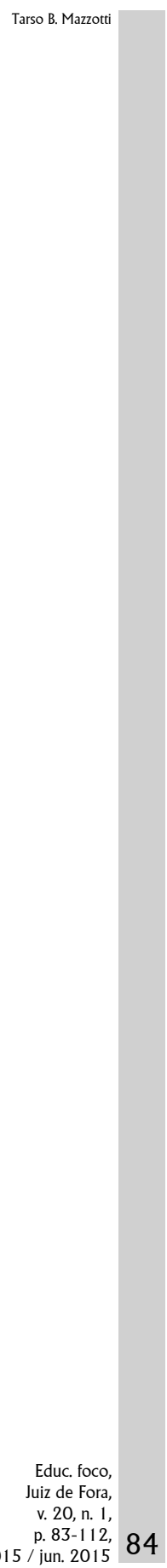

The author examines the problem of scientifically of Pedagogy (Education), which is the same for any science: the validity of induction, whose solution is to admit the effectiveness of the rules of modus tollens. These rules do not entirely solve the problem of validation of inductive inference, because the premises of its syllogism are supported in models, which are objects of dispute settled by negotiations of their meaning. These negotiations occur in rhetorical and dialectical social situations, from which result the organized knowledge for purpose of exposure (didascalia). For the author, the rhetorical, dialectical and logical (analytical) techniques constitute, together, the necessary conditions, although insufficient, for production and exhibition of scientific knowledge. He recalls that there are two types of science: the constructive and the reconstructive. The constructive sciences operate with selfreferent signs and have as object the operations on set of signs (logical and mathematical). While the reconstructive start out from comparisons to constitute some model, or metaphor, which allows them to apprehend and explain what they set up as object. The author includes the Rhetoric among the reconstructive sciences and sustains that it examines the limits of the modal axiom common to the rhetorical, educational and so called poetical arts: it is possible to modify the beliefs, values and attitudes, that is the common object of those, whose science is the Rhetoric, which is also the science of the educative practices.

Keywords: Pedagogy; Science of Education; Rhetoric; Epistemology of the science of education. 


\section{RETÓRICA, A CIÊNCIA DA EDUCAÇÁO}

Por séculos a educação escolar preocupou um grupo restrito de pessoas: sacerdotes, filósofos, sofistas e moralistas. Com a ruptura entre o Estado e as confissóes religiosas, ocorrida no século XIX, particularmente com as revoluçóes norte-americana e francesa, as escolas mantidas pelo público tornaram-se laicas. A laicidade pôs o problema da educabilidade no âmbito do que se compreende por ciência, uma vez que nesta os argumentos são neutros a respeito de alguma teologia, moralidade, ou ideologia. Por isso Alexander Bain (1879), bem como Eduard Claparède (1908) excluírem da Ciência da Educação as questóes relativas às finalidades, sustentando no considerado próprio das ciências: o uso de modelos lógicos e matemáticos que têm validade para qualquer pessoa razoável. Este desejo, como se sabe, frustrouse. A Ciência da Educação foi rapidamente substituída por um grupo delas: as Ciências da Educação. Certamente não se resolve o problema da cientificidade por meio de declaraçóes, mas pelo exame das condiçôes necessárias, ainda que insuficientes, para produzir conhecimentos confiáveis. Esse exame, próprio da epistemologia, tem por objeto a justificação racional da inferência indutiva para qualquer conhecimento e, em particular, os que resultam de práticas, das técnicas ou artes.

A arte de educar póe imediatamente o problema das finalidades ao sustentar ser possível conduzir o educando de um estado menos para o mais educado, axioma modal que lhe parece característico e próprio. Este axioma, no entanto, não é particular dessa arte, pois as da política, dramaturgia, literárias, musicais, plásticas também supóe que o autor afete de alguma maneira os seus auditórios. No entanto, quando se trata das técnicas noéticas, as que afetam e procuram modificar os estados cognitivos e afetivos dos outros, geralmente se diz 
que as pesquisas não podem ser sustentadas nos métodos quantitativos, apenas nos qualitativos. Essa dissociação sustenta-se em um engano, como se verá a seguir.

\section{QUANTITATIVO VERSUS QUALITATIVO.}

Afirma-se que as pesquisas em Educação só podem ser qualitativas, pois o educativo náo se apreende pelo método quantitativo. Trata-se de um engano, pois qualquer ciência examina as qualidades do que póe para si como objeto. $\mathrm{O}$ objeto de uma ciência é o sujeito de seus enunciados, que o define por meio de um conjunto de qualidades consideradas próprias. Por exemplo, em Geometria, os objetos são as figuras que apresentam qualidades que as definem como geométricas. Em outras ciências o objeto é definido por propriedades que eventualmente podem ser quantificadas, sendo necessário estabelecer consensualmente a intensidade das qualidade, o que implica uma concepção de medida. Mas há casos em que a qualidade náo pode ser considerada em si e por si (absoluta), uma vez que é posta em uma relação. Neste caso se pode falar em propriedade relacional.

Em qualquer um dos casos, a definição do objeto é um momento do processo de instituição de uma ciência, quando se pergunta: o que é isto? Para responder, começa-se por alinhavar um conjunto de predicados ou categorias, ou atributos, ou qualidades que delimitam o isto. Afirma-se os significados de cada categoria, o que conduz a outras e pode resultar em um círculo infinito. Este é um dos trabalhos árduos dos cientistas, bem como de qualquer pessoa que queira operar com concisão e conclusividade (rigor). $\mathrm{O}$ que pode ser mostrado por meio de exemplos históricos, em que modos de estabelecer um isto conduz a alteraçóes significativas nos argumentos dos cientistas, como mostrou, por exemplo, Thomas Kuhn.

Para não fugir do âmbito das Ciências do Homem consideremos as posiçóes de Jean Piaget, que estabeleceu o estudo das condiçóes para a constituição de conhecimentos 
científicos a partir da investigação dos erros lógicos apresentados pelas crianças. Um silogismo elementar como $\mathrm{A}=\mathrm{B}, \mathrm{B}=\mathrm{C}$, entáo $A=C$ não é reconhecido por crianças pequenas, um erro que apareceu no âmbito do teste de inteligência de BinetSimon. Todavia crianças mais velhas consideram evidente aquele enunciado. Há, pois, uma distância entre dois momentos do desenvolvimento cognitivo, portanto é factível estabelecer a sua medida, que são os seus estágios de um processo que culmina na constituição de juízos completos do ponto de vista lógico. Mas dizer a diferença não a explica e é isto que interessa ao cientista, pois uma ciência expóe as razóes das variaçóes de alguma qualidade. É o que Piaget propóe ao apresentar as melhores explicaçóes para o observado em sua teoria acerca do processo de desenvolvimento cognitivo (e afetivo). Não é o caso, aqui, de expor a teoria proposta por Piaget, uma vez que utilizada para exemplificar a determinação de um objeto e o papel da medida de variaçáo de suas qualidades ou atributos. Aqui é suficiente dizer que os estádios cognitivos sáo uma medida do processo de desenvolvimento que culmina no lógico-matemático, ponto de equilíbrio de um sistema que tem por operador geral a adaptação (assimilaçáo e acomodação).

Provavelmente a afirmação de que os estágios cognitivos propostos por Piaget sáo uma medida do desenvolvimento do pensamento hipotético-dedutivo seja escandalosa para alguns, pois identificam medida com escala de razão. Por certo, a seriação dos estádios cognitivos propostos por Piaget não é uma escala de razão. A qualidade das condutas lógico-matemáticas que constituem os conceitos como os de conservação de massa, peso, volume etc. variam em um processo mensurável por uma escala ordinal, uma seriação: a etapa I antecede necessariamente a II e esta a III, com variaçôes no interior de cada estágio. É uma quantificação lógica com o operador existe tal o qual qualidade em certo estádio.

Em suma, pode-se dizer que qualquer ciência parte de métodos qualitativos para definir, estabelecer as qualidades do que afirmar ser seu objeto. A intensidade das qualidades 
permite medi-las de alguma maneira, o que requer os meios para identificar a intensidade daquelas qualidades, um problema posto como o da teoria das medidas. Isto conduz ao que se tem dito das Matemáticas, a de que são essencialmente quantitativas.

\section{AS MATEMÁTICAS SÃO QUALITATIVAS.}

Não é muito difícil encontrar quem diga, enfaticamente, que as Matemáticas são, essencialmente, quantitativas. $\mathrm{Na}$ Enciclopédia Einaudi, no volume dedicado ao tema "Dialética", o par "identidade/diferença” é examinado logo de início e o seu autor, Enrico Rambaldi, afirma que o conhecimento analítico é o matemático, logo o quantitativo é identificado com o saber analítico:

[...] a matemática ilustra bem este aspecto severo do saber analítico: na verdade, ela é decorrente do mundo do qual representa aspectos Objectivos per se, como relaçôes "quantitativas" entre (e de) objectos, verdadeiras mesmo que os homens náo existissem; a relaçáo quantitativa entre força e massas no sistema Terra/Lua, por exemplo, não é decerto apenas um modo subjetivo humano de conceber o mundo, mas sim, antes do mais, uma estrutura objectiva sempre idêntica a si própria; e isto vale também para as relaçóes quantitativas inteiramente em abstracto, e não só para suas valências físicas: a relação geométrica entre volume e raio de uma esfera tem uma forma de existência em si, mesmo que os homens não existissem... (v. 10, p. 13-14).

Dizer que os entes matemáticos são em si porque são quantidades é uma imensa confusão, pois, sendo em si expressam a qualidade absoluta, náo relativa, enquanto o autor afirmar serem "relaçóes 'quantitativas". A relação entre figuras geométricas são qualitativas que podem ser expressas por diversas relaçóes, dentre as quais o raio e o volume na 
esfera. A métrica da geometria é um momento da exposição

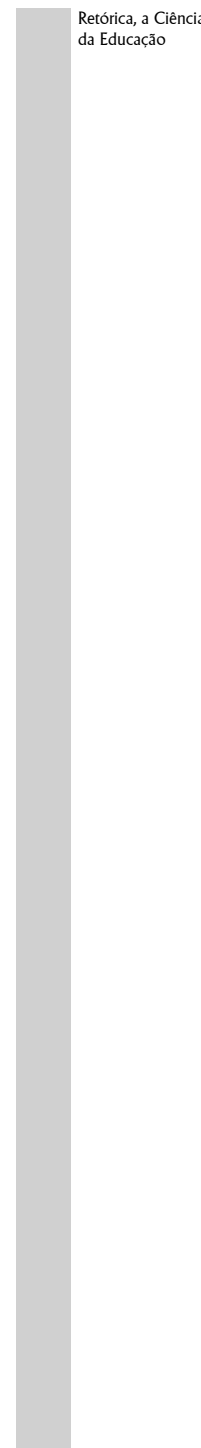
da figura e não se pode alcançá-la senão depois da análise das qualidades relativas entre si e estas não são métricas. Afinal, o que é uma esfera? No que difere do cubo; do paralelepípedo? Quais são as suas propriedades, atributos, qualidades? Além disso, o autor mistura as relaçóes da gravitação Terra/Lua, que expressam uma determinada qualidade, a queda dos corpos, no caso da Física newtoniana ou as curvaturas do espaço-tempo, no âmbito da teoria da relatividade restrita de Einstein, com sua expressão numérica. $\mathrm{Na}$ verdade, antes de estabelecer o cálculo foi preciso determinar a qualidade do objeto em pauta: a gravitação. Expressar a qualidade como uma relação multiplicativa e sua inversa é expor sua qualidade relacional, relativa, não em si e por si (absoluta), ainda que, no caso da Física newtoniana, o espaço e o tempo sejam considerados absolutos, portanto separados. O autor confunde a determinação da figuras (morfos) geométricas com os procedimentos de medida que servem para definir certas qualidades das figuras. No mesmo volume, René Thom, matemático, contesta indiretamente as posiçôes de Rambaldi, em seu verbete Qualidade/Quantidade (p. 226-241), o qual, em sua conclusão, remete a Enrico Berti quando afirma que o "realce posto na quantidade em detrimento da qualidade procede de uma vontade filosófica unificadora" (p. 240), a ambição das metafísicas e religióes. De fato, o problema não se encontra na adoção das Matemáticas como "paradigmas" de cientificidade, ainda que esta atitude tenha provocado, e ainda provoque, muitos enganos. Como será examinado a seguir na habitual comparação entre as ciências naturais e humanas.

\section{O HOMEM INVISÍVEL E OS ÁTOMOS VISÍVEIS.}

Muitos assumem que as ciências naturais são quantitativas; logo, incompatíveis com o conhecimento do humano, que só pode ser qualitativo. A seguinte afirmação exemplar permite sua apresentação sumária. Rubim (1993, p. 427 , grifado no original) afirma que ao se tomar por objeto o 
homem vê-se "[...] as manifestaçôes de seu ser mais profundo, mas aquela dimensão do ser que produz tais manifestaçóes não é imediatamente visível". Parece que o autor desconhece os processos de investigação das ciências naturais. Afinal ninguém vê os elétrons, prótons e nêutrons, mas as suas manifestaçóes em placas fotográficas, os raios X, ou os traçados na "câmara de vapor de Wilson". Como a "natureza profunda" da matéria só se deixa apreender por suas manifestaçóes, pode-se afirmar que não há diferença entre as duas ordens de fenômenos. Considerar de outra maneira seria dizer que o humano é invisível e os átomos visíveis. O centro do debate contemporâneo acerca do caráter do conhecimento científico e sua difusão foi posto pela invisibilidade dos átomos e não dos homens. Isto porque não é possível afirmar, com certeza dedutiva, quais são as suas qualidades. De fato, o que se diz acerca dos átomos, bem como de qualquer fenômeno, não expressa a "verdadeira" natureza do objeto, mas do que se julga ser o modelo ou metáfora adequado e pertinente ao que se observa de maneira controlada (experimento).

Se o que se diz acerca das coisas é um modelo, um artefato, então sua aceitação seria uma questão de moda? Há critérios intersubjetivos (objetivos) para validar as explicaçóes? As novas teorias seriam um prolongamento das antigas? Elas romperiam com as anteriores de tal maneira que são inconciliáveis?

\section{A SUBSTITUIÇÃO DE PARADIGMAS NAS CIÊNCIAS RECONSTRUTIVAS.}

Thomas Kuhn, em 1961, sustentou que a história das ciências mostra que a relação entre teorias concorrentes é o de substituição de paradigmas. A substituição de paradigmas ocorre pela adesão crescente de adeptos, que são os jovens cientistas pouco comprometidos com o paradigma dominante (ciência normal). Os adeptos, com o tempo, passam a controlar os postos universitários, os laboratórios, os recursos financeiros, 
bem como o ensino da disciplina, produzindo novos manuais baseados na teoria emergente. Esse processo exclui os participantes da "velha teoria", assim como os que adotam alguma "teoria alternativa". Os cientistas que discordam do "novo paradigma" náo têm como fazer valer as suas vozes, uma vez que as instituiçóes estáo tomadas pelos adeptos do paradigma vencedor, que se torna a "ciência normal", até que surjam novos propositores, ("ciência revolucionária") e o ciclo recomeça. Assim sendo, haveria um corte entre a ciência normal e a revolucionária, ou entre o "paradigma vigente em dado momento", e o emergente, inexistindo continuidade ou acumulação de conhecimentos.

Se é fato que há substituição de paradigmas, então se pode sustentar que há rupturas conceituais? Estas rupturas permitiriam sustentar que as teorias científicas são incompatíveis? Caso se afirme que as teorias antigas e as novas são incompatíveis, entâo nấo há um processo de acumulaçáo de conhecimentos e o problema passa a ser o da explicaçáo da adesão ao novo. A adesão seria uma questão de gosto? Como um paradigma consegue ser hegemônico?

Recorde-se que a noçáo de paradigma descreve redes sociais: um conjunto de procedimentos, de relaçóes interpessoais, institucionais sustentam uma teoria. Paradigma não é uma teoria, é o nome das relaçôes sociais que sustentam uma teoria. Kuhn afirmou que as decisões acerca do valor de uma teoria científica não necessariamente se sustenta nos procedimentos lógicos, como o modus tollens, mas nas relaçóes interpessoais dos cientistas. Opunha-se ao empirismo lógico de Ernest Mach, que coordenou conceitualmente o grupo conhecido por Círculo de Viena, que pretendia desenvolver a unificação das ciências. O empirismo lógico, ou positivismo lógico, sustenta que o conhecimento científico independe das relaçóes intersubjetivas ou sociais. Isto porque o método de pesquisa é capaz de resolver os problemas conceituais e fornecer as explicaçôes, por isto, é o método discursa, náo os cientistas. Se é o método discursa, então os cientistas não podem ser 
considerados retóricos, ou ideólogos, pois expressam a verdade dos argumentos sustentados em alguma lógica, exatamente o que pretendiam os fundadores da Ciência da Educação. Neste registro, o método científico anula o sujeito, exclui a subjetividade e intersubjetividade. $\mathrm{O}$ que justificaria a adesão dos cientistas a uma nova teoria, eles são convencidos pela validade dos enunciados lógicos, racionais, e não por aderirem a este ou aquele grupo social. Esta a filosofia das ciências questionada por Kuhn, o que conduziu à proposição de o conhecimento científico ser socialmente construído, o que será examinado a seguir.

\section{A CONSTRUÇÃO SOCIAL DO CONHECIMENTO CIENTÍFICO.}

$\mathrm{Na}$ linha de desenvolvimento da proposição de o conhecimento científico ser socialmente construído como qualquer outro, institui-se a Sociologia do Conhecimento Científico. Os sociólogos do conhecimento científico mais conhecidos são Barry Barnes, David Bloor, Steven Shapin, Harry Collins, Bruno Latour, Steve Woolgar, Karin Knoor Cetina. Para eles os fatos científicos são inventados pelos cientistas, não são uma exposição acurada da realidade, como desejaria o apriorismo filosófico, ou seja, o empirismo lógico (ver, por exemplo, CALLON, 1989; PICKERING, 1992). Callon (1989, p. 173) mostrou que o Laboratório de Beauregard, dedicado ao estudo das pilhas combustíveis, sustentou-se por muito tempo sem apresentar qualquer resultado valioso. Por isso o sociólogo concluiu:

A construção dos fatos científicos é inseparável dos atores sociais, simplesmente porque os pesquisadores colocam-se, simultaneamente, a questão da fabricação de enunciados ou de novos dispositivos, bem também de sua difusão e aceitação (CALLON, 1989, p. 209). 
Não há, pois, algum critério que permita distinguir a adoção e a difusão de uma ideologia e a de uma teoria científica, salvo seus nomes. É inegável que uma teoria científica percorra os caminhos da cooptação de novos membros.

Mas esta constatação permite dizer que não há critérios de validação dos conhecimentos científicos? A adesão a um paradigma não seria racional? Muitos respondem afirmativamente apoiando-se em Kuhn para afirmarem um relativismo radical. Neste caso, o mesmo relativismo conduz a dizer que os conhecimentos produzidos por aqueles sociólogos também resultam de negociaçôes, sem que se tenha algum critério para os admitir (PICKERING, 1992, p. 19). Chegase a uma aporia: os enunciados da sociologia do conhecimento científico são invençôes dos sociólogos que montaram as múltiplas redes de relaçôes sociais que sustentam suas posiçôes.

Como essas disputas apresentam-se no âmbito dos debates acerca da cientificidades da Educação (Pedagogia)?

\section{A GUERRA DOS PARADIGMAS EM EDUCAÇÃO.}

Os debates em torno dos chamados paradigmas de pesquisas em Educação foram caracterizados como uma "guerra dos paradigmas" (GAGE, 1989), que se desenrola tendo por tema a crítica do "positivismo". Essas críticas conduziram ao aparecimento de correntes que têm sido denominadas "pós-positivistas", "teóricos críticos" e "construtivistas" (norte-americanos), além de outras como a dos que se autodenominam de "pós-modernos" ou "pósestruturalistas". Alves-Mazzotti (1998), em sua revisão do debate entre as diversas correntes metodológicas da pesquisa em Educaçâo indica que as divergências entre os pós-positivistas, os teóricos críticos e os construtivistas ocorrem em torno da compreensão da possibilidade de generalizaçáo e acumulaçáo de conhecimentos, bem como em torno da "acomodação entre paradigmas", o que pode ocorrer quando se tem por objetivo a realização de alguma coisa, o que se pretende fazer. Assim 
a autora relativizou o relativismo ao introduziu um critério pragmático para a acomodação de paradigmas concorrentes: o da finalidade ou objetivo das investigaçóes. A autora concorda com Austin, para quem é possível algum tipo de acomodação entres os paradigmas, que ele compreende como teorias, todavia não considera possível alguma acomodação no nível ontológico e/ou da teoria do conhecimento (ALVESMAZZOTTI, 1998, p. 143). Isto porque as teorias seriam contraditórias e incompatíveis.

Há contradição entre teorias? Paradigmas incompatíveis podem ser compatibilizados? Para responderé preciso considerar o que se entende por contradição e incompatibilidade.

\section{CONTRADIÇÁO OU INCOMPATIBILIDADE?}

Não há como estabelecer contradição entre teorias, apenas enunciados podem ser contraditados e as teorias são conjuntos sistematizados de proposiçóes ou enunciados. Há contradição quando o sujeito de um enunciado recebe predicados contrários em uma mesma situação. Por exemplo, não há como sustentar que alguém cometeu e não cometeu um crime na mesma situação de acusação. De outro lado, argumentos que têm validade em uma situação podem ser incompatíveis em outra. A incompatibilidade não se resolve por meio de argumentos que visam estabelecer a verdade, mas por sua pertinência à situação (PERELMAN; OLBRECHTSTYTECA, 2008, $\$$ 48, p. 262). Considerando, com Kuhn ${ }^{2}$, que paradigmas são crenças, atitudes e valores, então as incompatibilidades decorrem do que se pretende fazer em uma situação. Por exemplo, a mecânica estabelecida por Newton mantém sua pertinência e validade na escala próxima

2 Convém recordar que Kuhn fala de incompatibilidades, não de contradições entre "paradigmas", por exemplo: "Each of them necessitated the community's rejection of one time=honored scientific theory in favor of another incompatible with it” (Kuhn, 1996, p. 6). 
e não para outras, ou as teorias válidas em seus espaços de parâmetros deixam de ser em outros.

Além disso, decisão acerca da incompatibilidade é do âmbito da retórica, do que as pessoas consideram preferível fazer ou ter (valores), não se refere a enunciados contrários que precisam ser eliminados para se obter um conhecimento confiável, o que é próprio da situação dialética, na qual se põe o problema da indução.

\section{O PROBLEMA DA INDUÇÁO.}

O cerne do debate que emergiu da obra de Kuhn está na afirmação relativista radical de que não é possível estabelecer algum critério que permita determinar o valor de verdade ou confiabilidade de uma teoria. Isto porque a adoção de uma teoria não depende de critérios lógicos, metodológicos e epistêmicos, mas dos sujeitos cooptados. Afirma-se, então, que a precariedade da indução impede que se decida o valor de uma teoria. É fato que a partir de uma coleção de particulares a generalização é precária, há limites para a inferência indutiva, porém isto não implica a impossibilidade de prover conhecimentos razoáveis e confiáveis acerca de algo. Estes conhecimentos não são as certezas dos enunciados dedutivos, que se sustentam em signos utilizados no cálculo lógico ou no matemático, próprio das ciências formais, que são diversas das reconstrutivas, as não formais, como as que tratam dos fenômenos naturais.

No caso das ciências reconstrutivas, as premissas de seus silogismos são proposiçóes apresentadas na forma de sujeito e predicado. Os predicados estão disponíveis na língua e permitem dizer quais sáo os limites do sujeito (da frase), individualizando-o. Ao dizer "homem é mortal", afirma-se: o homem pertence à classe (categoria), dos seres que morrem e supõe que há seres que não morrem. Como homem é uma designação geral, uma classe de todos os seres que apresentam certas qualidades, então é preciso saber quais são elas. As 
qualidades definidoras precisam ser únicas, não pertinentes a outros seres. A qualidade mortal é compartilhada pelos seres vivos, portanto não é específica do homem. Qual, ou quais seriam as qualidades específicas do sujeito da proposição: homem é mortal? A diferença específica de homem é objeto de disputas. A decisão a respeito da sua definição, as suas diferenças específicas, produz debates inconclusivos em torno das premissas primeiras (princípios), que são o tema das metafísicas e religiôes, nas quais dificilmente se pode decidir com base no silogismo sob a figura do modus tollens. Este permite encontrar a melhor explicação, dizer as razóes ou causas do afirmado na premissa maior. Tome-se um exemplo de argumento retórico baseado em signo: se tem leite (signo), então deu à luz. Caso exista apenas um caso que refute esta conclusão, então esta não pode mais ser admitida. Foi o caso, logo se buscou a melhor explicação para a lactação por meio dos procedimentos do diálogo regulamentado (dialética) que eliminou as hipóteses concorrentes e isolou a que melhor explica a lactação e este é um conhecimento científico, que se encontra exposto nos manuais de fisiologia animal. Ainda que os relativistas radicais desconsiderem o modus tollens, os conhecimentos confiáveis dependem desse procedimento.

A questão-chave passa a ser: de onde são retirados os predicados utilizados para a constituição dos silogismos na investigação? As ciências reconstrutivas recorrem a enunciados cujas premissas são postas na forma de silogismo dialético e retórico, enquanto as formais operam por meio de cálculos sobre signos, uma diferença específica que precisa ser exposta.

\section{CIÊNCIAS CONSTRUTIVAS E RECONSTRUTIVAS.}

Nas ciências formais, as Matemáticas e as Lógicas, argumenta-se por meio de cálculos sobre signos definidos pelos cientistas, por isso são construtivas, pois seus conhecimentos são um conjunto auto-sustentável. As demais ciências são reconstrutivas, uma vez que os fenômenos são reconstituídos 
por meio de modelos, ou metáforas, considerados adequados e pertinentes, os quais fornecem os predicados dos enunciados de seus silogismos. A tarefa básica nas ciências reconstrutivas é a de verificar se o modelo descreve os fenômenos de maneira pertinente. Caso uma ciência reconstrutiva utilize um modelo retirado de uma Matemática, este só terá valor caso efetivamente descreva e explique os fenômenos.

Como as ciências reconstrutivas são constituídas e expostas por meio modelos geométricos, topológicos ou de redes (reticulados e outros grafos), então há a tendência de julgar que o exposto é a coisa representada e esta é matemática. $\mathrm{O}$ enunciado da Física na forma $\mathrm{f}=\mathrm{m}$. a póe-se como a explicação de força e os cálculos surgem como se fossem a própria coisa. De fato, trata-se de uma definiçáo de força por meio do produto cartesiano de massa e da aceleraçáo. Ela define a força como relação, não algo essencial, em si e por si, mas relativo à massa e à aceleração. Neste caso, não se tem uma relação na forma sujeito e predicado? A definição relacional afirma que o sujeito "força" é o mesmo que a multiplicação de "massa" e "aceleração", que operam como predicados, em uma ontologia relacional, relativista. O que nos leva a perguntar: o que é massa? O que é aceleração? Estes nomes também são definidos por meio de relaçôes, que operaram como predicados. Não se trata, pois, de "matematização", mas do uso de algum conceito produzido no âmbito de uma matemática para definir e eventualmente explicar um fenômeno. Este procedimento não difere do uso dos esquemas argumentativos capitulados na Retórica, a diferença específica encontra-se nas exigências de concisão e conclusividade requerida em cada situação, ou seja do rigor argumentativo admitido pelos cientistas, o que estabelece um gênero retórico, o das ciências (PERA, 1994).

Kuhn tem razão ao dizer que os paradigmas científicos são substituídos quando as suas anomalias não podem ser resolvidas, mas o problema está na escolha da teoria sustentada pelo paradigma. Os critérios para essa escolha encontram-se na análise das inferências utilizadas e nas ciências reconstrutivas 
não é um problema formal, mas o da escolha da metáfora da qual se retira os predicados utilizados para constituir os termos dos silogismos para dizer as razóes, ou causas, de algum evento ${ }^{3}$. Considere os debates acerca das qualidades fundamentais da matéria, que ocorrem no início do século $\mathrm{XX}$, em que Weinberg sustentou ser composta por partículas elementares que se comportam como se fossem um "enxame de insetos". Seus opositores ironicamente disseram tratar-se de uma "zoologia". Essa objeção conduziu os físicos a compararem os movimentos observados com o inanimado (HOLTON, 1995; 1982). A melhor comparação é com o conjunto dos números aleatórios que permite calcular a probabilidade de as "partículas" estarem em uma zona do espaço em observação (espaço de parâmetros).

Em suma, no âmbito das ciências reconstrutivas, assim como em outras situaçôes comunicativas, a substituição de seus modelos altera os argumentos, pois suas premissas obtém seus significados de metáforas diferentes das anteriores, o que levou Kuhn a dizer que paradigmas são incomensuráveis. De fato, os modelos podem continuar sendo utilizados em uma situação, não em outras, isto porque o que define a pertinência não é o modelo, mas o que se pretende fazer, o que não é um problema puramente formal, mas de decisóes tomadas pelo coletivo dos cientistas em uma situação de diálogo regulamentado. Agora é preciso recordar o conceito de estrutura que se encontra subjacente ao que vem sendo apresentado.

\section{CONCEITO DE ESTRUTURA DAS CIÊNCIAS CONSTRUTIVAS ÀS RECONSTRUTIVAS.}

As ciências construtivas examinam estruturas conceituais. A estrutura imediatamente compreensível é a da frase, que apresenta forma, ou estrutura, sujeito e verbo, em que este opera as relaçóes linguareiras.

3 A escolha dos modelos é um tema que tem sido tratado por autores como Black (1972 [1962]), Waddington (1979), Wolfram (2002). 
As ciências construtivas têm por objeto as estruturas

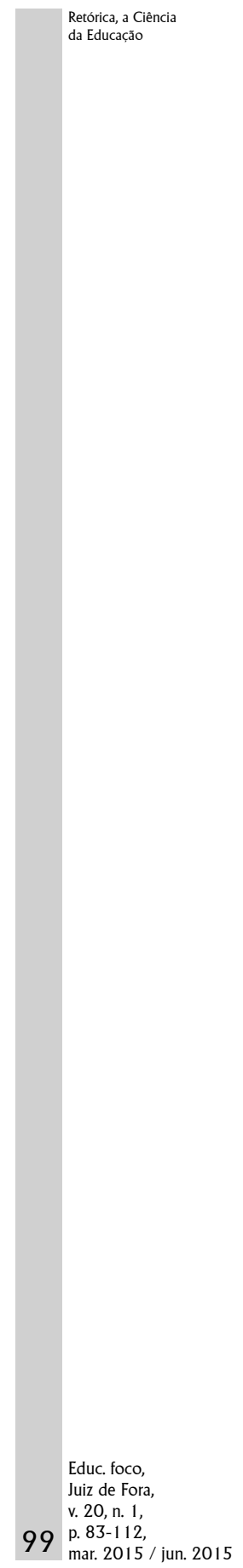
matemáticas e lógicas sustentada por alguma de base e suas transformações. Denomina-se "estrutura" o máximo de propriedades que um operador apresenta sobre um conjunto de elementos, como os números. É o caso da adição sobre o conjunto dos números racionais. Se a adição for aplicada ao conjunto dos números racionais, entâo apresentará as seguintes propriedades: associativa, comutativa, elemento neutro (zero) e elemento inverso $(-n)$, tem-se entáo a estrutura dita grupo comutativo. Caso a adição seja aplicada sobre o conjunto dos número naturais sem o zero, então será um monóide comutativo, pois apenas as duas primeiras propriedades estão presentes. Os conceitos da estrutura algébrica podem ser tomados por modelos para estudar operadores sobre algum conjunto não numérico, por exemplo, a estrutura de parentesco, tal como o fez Lévy-Strauss; bem como as estruturas cognitivas, que se encontram na proposta de epistemologia genética devida a Jean Piaget.

Certamente há modificações significativas quando se toma as estruturas algébricas como modelos para descrever e explicar relaçóes distantes do cálculo algébrico, mas os autores aproximam a noção de operador algébrico aos que encontram nas relaçóes que estudam. Tome-se o caso da epistemologia genética, em que as operaçóes cognitivas são apresentadas em um processo que se inicia por esquemas sensório-motores, portanto ainda não são estruturas, culminam com estruturas lógico-matemáticas. Afirma-se que há uma construção, tal como se pode dizer que ocorre nas ciências formais. Esta é uma ilustração da apropriação do conceito de estrutura algébrica por uma ciência reconstrutiva, mas o uso do conceito de estrutura não implica transformaçóes estruturais análogas às algébricas, salvo se houver algum teorema que permita afirmar a equivalência, o que foi rejeitado por Piaget, para continuar no exemplo. De fato, o pesquisador reconstitui um processo utilizando um modelo que permite descrevê-lo e explicá-lo, sem assumir que se trata de uma álgebra ou que seria possível 
prever as passagens antes da investigação. Não é o caso aqui de desenvolver esta afirmaçáo, que foi tema de um debate entre Apostel e Piaget (ver, por exemplo, PIAGET;GARCIA, 1987, p. 168).

De outro lado, o desenvolvimento as ciências construtivas e as reconstrutivas percorrem vias próprias. Nas ciências construtivas faz-se por meio de transformaçóes estruturais que permitem generalizaçóes mais amplas que contêm as anteriores. Nas reconstrutivas as mudanças ocorrem pela substituição de modelos segundo as necessidades postas pelas situações. Thomas Kuhn, ao examinar a história de uma ciência reconstrutiva, a Física, mostrou a substituição de paradigmas, mas isso não ocorre nas construtivas. Nestas, os limites da formalização, demonstrados por Gödel, deu origem a outra via para o formalismo: o algoritmo (BERTO, 2009). O algoritmo é uma sequência de instruçóes não ambíguas e bem definidas que podem ser executadas mecanicamente durante certo tempo e que pode ser realizada por um humano, ou por uma máquina. Os algoritmos permitem descrever e conformar as atividades, bem como antecipar eventos que descreve, o que conduz ao exame das práticas humanas.

As práticas humanas apresentam dois aspectos sob os quais são avaliadas: o da efetividade (eficácia e eficiência) e o antecipatório. A antecipação da ação, a inferência, sustentase no que se diz acerca das práticas, portanto no modelo ou metáfora conceitual em uso, da qual são retiradas as premissas de seus silogismos. O que se diz ser as premissas dos silogismos depende do foro de onde são retirados os significados para o tema. As ciências reconstrutivas sustentam suas inferências nos quadros conceituais que consideram pertinentes ao real, tal como se faz em outras situaçóes sociais, mas destas diferem por utilizarem conscientemente o a figura modus tollens do silogismo. Mas há um discurso que se apresenta como estando para além ou aquém dessas disputas: o silogismo categórico. 


\section{DISCURSO PARA ALÉM OU AQUÉM DO HUMANO.}

Geralmente se considera que a negociação dos significados é a expressão da fragilidade dos argumentos, uma vez que está condicionada pelos grupos sociais. Afirma-se, então, que o próprio da filosofia e da ciência é o discurso que persuade qualquer pessoa por ser a expressão de um vínculo de raciocínio que está para além ou aquém dos grupos sociais e são apresentado na forma silogismos categóricos, e quando não é assim, afirma-se o relativismo radical.

A fonte dessa concepção encontra-se nos Analíticos Anteriores e Posteriores, nos quais Aristóteles apresenta os instrumentos técnicos para a exposição que requer certa independência da éndoxa ${ }^{4}$. É o caso do discurso do ensino (didascália), em que o orador fala e o ouvinte só pode ter a atitude de aprendiz, a de aceitação do que é enunciado5 ${ }^{5}$ Uma apresentação rigorosa é uma técnica que requer a sistematização das afirmaçóes encadeando-as de tal modo que cada uma seja necessária à outra para garantir a correção do que se propóe ensinar. Como toda técnica, a de exposição é contingente e, portanto, tem limites, é dependente do auditório, isto porque as regras silogísticas não são espontâneas, precisam ser aprendidas. Do que resulta uma circularidade: para aprender uma ciência é preciso conhecer a ciência, tal como no paradoxo de Mênon. A solução é: aprende-se as técnicas

4 Aristóteles, nos Tópicos (100 b 24), define éndoxa como opinióes "geralmente aceitas [...] por todos, ou pela maioria ou pelos filósofos, isto é, por todos, ou pela maioria ou pelos mais notáveis e ilustres dentre eles".

5 "Toda didascália e toda disciplina dianoética [intelectual, cognitiva] se adquirem de um saber que precede o conhecimento. Isto é evidente seja qual for o saber considerado: a ciência matemática adquire!se desse modo, tal como as outras artes. O mesmo acontece com os raciocínios dialéticos, sejam eles feitos por silogismo ou por indução, porque todos eles ensina através de um conhecimento anterior; no primeiro caso, assumindo que as premissas são admitidas pelo outro, no segundo caso, demonstrando o universal mediante o particular já conhecido. De outro lado, é de análogo modo que os argumentos retóricos persuadem, uma vez que utilizam ou paradigmas, o que é uma espécie de indução, ou entimemas, o que não deixa de constituir um silogismo", Aristóteles, Analíticos Posteriores, I, 71a.

Educ. foco, Juiz de Fora v. 20 , n. 1 , p. $83-112$, mar. 2015 / jun. 2015 
argumentativas utilizando-as. Não se as aprende de imediato e em sua totalidade, mas progressivamente pela imitação dos atos técnicos, particularmente resolvendo os problemas conforme são postos pela imitação.

O exame das premissas dos argumentos é condicionado pelas instituiçóes que determinam o seu grau de liberdade. Nestas, algumas premissas são consideradas fundadoras e indiscutíveis, outras podem ser questionadas. Por isso, quanto maior a liberdade dos membros de uma instituição, maior é a probabilidade de aparecerem os que questionarão os princípios admitidos, uma vez que não serão censurados, desde que sigam as regras próprias de cada tipo de questão. Como as regras universais dos argumentos são as do silogismo, há os que propóem que este é uma máquina que descarta o orador e se impóe ao auditório.

\section{SILOGISMO, MÁQUINA QUE DESCARTA O ORADOR E SE IMPÓE AO AUDITÓRIO.}

Uma vez que qualquer argumentação apóia-se em algum tipo de silogismo, pode-se dizer que silogismo é próprio do racional. A recuperação da retórica por Perelman tem uma origem: os procedimentos próprios da lógica são cálculos que substituem o homem na produçáo e desenvolvimento de conhecimento ou, parafraseando Quine (1953), a lógica deve substituir o cientista, deve conduzir o pensamento de modo automático, como uma máquina conceitual, que de fato é.

No entanto, no interior da lógica proposicional surgiu um problema insolúvel, o da implicaçáo material ou condicional. Isto porque, nos julgamentos ditos "condicionais": de um enunciado em que antecedente falso e o consequente é verdadeiro, obtém um enunciado verdadeiro (ver a tabela 1). Por exemplo: em "as vacas voam" (A) e "as vacas são herbívoras" (B) é uma condicional verdadeira, forma $\mathrm{A} \rightarrow \mathrm{B}$ é válida. Alguns lógicos (Quine, por exemplo) dirão que devemos abandonar a expressão "se...entáo", deixar a forma 
dominar o pensamento descartando o conteúdo material, mas na pratica científica isso seria um absurdo ${ }^{6}$.

Tabela 1

Tabela verdade da condicional

\begin{tabular}{c|c|c}
\hline $\mathrm{A}$ & $\mathrm{B}$ & $\mathrm{A} \rightarrow \mathrm{B}$ \\
\hline $\mathrm{V}$ & $\mathrm{V}$ & $\mathrm{V}$ \\
\hline $\mathrm{V}$ & $\mathrm{F}$ & $\mathrm{F}$ \\
\hline $\mathrm{F}$ & $\mathrm{V}$ & $\mathrm{V}$ \\
\hline $\mathrm{F}$ & $\mathrm{F}$ & $\mathrm{V}$ \\
\hline
\end{tabular}

De outro lado, as tentativas para formalizar completamente o Direito, procurando tomar decisóes automáticas, enfrentaram problemas ainda mais graves. Ao buscar superar tais dificuldades iniciou-se um movimento que procurou examinar a assim chamada "lógica natural", na qual as lógicas se sustentariam, e que retomou Aristóteles (BERTI, 1997) chegando à proposição de que as premissas dos silogismos resultam de uma negociação de seus significados, a qual ocorre, de início, na situação retórica (ver, WOLFF, 1995), que também recorre ao contraditório ou às técnicas da dialética, o que será apresentado a seguir.

\section{A SITUAÇÃO RETÓRICA: NEGOCIAÇÃO DOS PREDICADOS DAS PREMISSAS.}

Não é o método que discursa, mas pessoas que questionam as respostas. E o questionamento é uma negociação de significados realiza-se na situação retórica, que inclui a dialética.

A negociação inicia-se pelo dizer o que é a partir do exame dos discursos que pretendem instituir seus significados, procurando a ocorrência do erro argumentativo petiçáo de

6 Perante este impasse foram propostas outras lógicas bem formadas que procuram solucionar o problema da implicaçáo, dentre elas a de Anderson e Belnap (1975), bem como a de Da Costa (1980). 
princípio (ver PERELMAN; OLBRECHTS-TYTECA, $2008, \$ 28)$. Ao dizer o que é algo, estabelece-se os predicados (categorias) que delimitam o que se negocia, por meio do contraditório. Quem afirma que o sujeito (tema) apresenta tais ou quais qualidades (predicados, atributos, propriedades) o faz por meio da transferência de significados do já sabido ao que ainda não se sabe, o que pode produzir uma metáfora ou um modelo.

A metáfora não é uma apenas figura ornamental, mas cognitiva, expressiva e praxiológica. Cognitiva, por aproximar o não similar por meio da transferência de certos predicados de um objeto ao outro. Expressiva, ao expor o desejável ou o indesejável para um grupo social. Praxiológica, por orientar o que deve ser feito. Uma vez admitida uma metáfora, estabelece-se um acordo que determinará o vínculo de raciocínio (CHARBONNEL, 1991 a, 1991 b, 1993, 1999). A identificação das metáforas cognitivas requer a análise retórica, a que expóe o que o orador e o auditório consideram estabelecido, assim como as razóes das disputam acerca dos significados. Pode-se, então, sustentar que as técnicas que procuram, de alguma maneira, afetar os homens não são apreendidas pela análise lógica, porque esta se limita a expor os vínculos válidos dos discursos, ainda que relevante, não permite apreender as relaçóes entre o orador, o auditório e o discurso por meio das quais negociam suas diferenças e os processos de influência ou persuasão. Os procedimentos para produzir os conhecimentos confiáveis não são os utilizados para os expor, os quais Aristóteles tratou nos Analíticos Posteriores e que constituem o horizonte do ensino e que póe em cena a Pedagogia. Esta seria uma ciência reconstrutiva da prática educativa? 


\section{PEDAGOGIA, CIÊNCIA RECONSTRUTIVA DA PRÁTICA EDUCATIVA.}

Se a Pedagogia, condição reflexiva da prática educativa, for uma ciência reconstrutiva, então seus argumentos serão produzidos a partir de comparaçóes, como em todas elas, e procurará estabelecer os modos eficazes e eficientes para modificar as crenças, valores e atitudes dos educandos. Mas isto não é um território exclusivo da pedagogia, pois a política, a dramaturgia, a poética, a música, a pintura e a escultura são técnicas que visam alterar as crenças, valores e atitudes.

Porém há uma grande controvérsia acerca da eficácia e eficiência (efetividade) dessa meta em todas essas técnicas, que tem origem na análise da afirmação modal: é possível modificar crenças, valores e atitude, uma vez não diz como, nem se é necessário, apenas afirma algo presumidamente verificável. Sabe-se que algumas vezes é possível conduzir os outros a certas reflexóes, pois já ocorreu com cada um ser afetado por leituras, debates, avaliação de algum trabalho e pela aprendizagem. E esta convicção é questionada sempre que se procura passar do "possível" ao "necessário".

A negação da efetividade dos atos técnicos noéticos assume, então, seu papel. Há, pelo menos, duas atitudes céticas: (1) a que sustenta ser impossível modificar intencionalmente os valores, as atitudes e as crenças dos outros, porque as palavras são interpretadas de maneira diversa; (2) a que sustenta que as pessoas são tomadas por forças que não podem ser totalmente apreendidas, o que impede que algumas açóes intencionais produzam as alteraçóes pretendidas.

Afirmar que as palavras não são capazes de realizar por inteiro a comunicação, que os outros apreendem-nas segundo seus quadros conceituais, por isso não se pode ter certeza da eficácia dos discursos, foi inicialmente, pelo que se sabe, proposta por Górgias de Leontini. Górgias sustentou o poder de mobilização da retórica, mas também expôs os seus limites, que foram apresentados por Sextus Empiricus em Adversus 
Mathematicos (HANKINSON, 1995, p. 83), onde se lê que “os discursos não são as coisas que subsistem”, logo a palavra não têm o poder de modificar os ouvintes. Há limites para ação do orador: ele é incapaz de modificar o inegociável para o auditório. Por isso, Górgias e outros concluíram que um conhecimento verdadeiro sobre o mundo é impossível e o discurso persuasivo sempre será uma réplica do já sabido.

A segunda posição cética sustenta-se na inatingível essência do homem que move o homem. Neste caso efetividade de uma ação educativa explica-se pela coincidência (a incidência conjunta) do orador com o auditório. Os ouvintes não modificam suas crenças, valores e atitudes pela ação do orador, apenas os reforçam, tal como no Paradoxo de Mênon: não se ensina, ajuda-se o outro expor o que se encontra em si. Uma variante contemporânea considera que o inconsciente é inacessível. Nesta perspectiva, o analista reflete (em seu significado de especular) o que o paciente apresenta ajudando-o a tomar consciência das forças ocultas que o movem. $\mathrm{O}$ analista não modifica essas forças; ele ajuda o paciente a explicar para si o que está em curso.

Em qualquer dos casos afirma-se os limites da ação que pretende modificar as crenças, as atitudes e valores, que se sustenta no axioma modal, o que póe em presença a ciência constituída com base nos limites da técnica de negociação de significados: a Retórica.

\section{RETÓRICA, CIÊNCIA DOS LIMITES DA COMUNICAÇÁO.}

A Retórica é ciência dos limites da arte de persuadir ou influenciar as pessoas. Aristóteles, em seu tratado, apresenta a Retórica afirmando ser a ciência que tem por objetivo encontrar o persuasivo em uma situaçáo a partir do espontaneamente realizado pelos oradores eficazes e eficientes. A Retórica é um conjunto de conhecimentos confiáveis capaz de orientar o trabalho do orador em sua busca do discurso que mova o auditório na direção por ele desejada. E, como em qualquer 
outra técnica, é preciso ajustar o idealizado às condições de sua

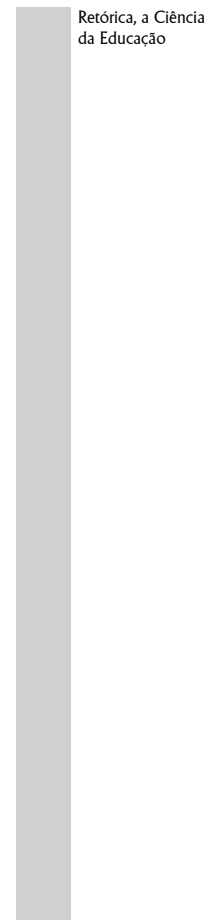
realização, o que é um conhecimento confiável a respeito das técnicas. Ou seja, a incompletude das artes é a condição de sua ciência, a que busca sistematizar os conhecimentos a partir de seus limites.

Em suma, a partir da convicção de que é possível modificar as atitudes, crenças e valores, que tem origem na experiência de cada um, não se alcança a certeza categórica, isto porque o axioma modal diz muito e quase nada. A superaçáo dessa limitação é factível pelo reconhecimento de que se está em uma situação retórica, a contrapartida da dialética, própria de qualquer grupo humano. Nesse caso, o conhecimento é validado pela observância das regras argumentativas estabelecidas ao longo da história e mantidas em um dialogo permanente entre os membros dos grupos sociais. Pode-se afirmar que as práticas educativas são um caso particular arte retórica, que a Retórica é a ciência da Educação ou Pedagogia, condição reflexiva daquelas ações.

\section{RETÓRICA, A CIÊNCIA DA EDUCAÇÁO.}

O axioma modal da Educação (Pedagogia) é o mesmo da Retórica e explicita seu caráter contingente. A contingência não é exclusiva das técnicas sociais, em todas há limites postos pelas particularidades, o que legitima a afirmação corrente: "na prática, a teoria é outra”. O reconhecimento da contingência expressa a posição pragmática de que sempre se ensaia fazer algo de um modo perfeito e completo, mas nunca se alcança completamente o desejado. Similarmente as explanaçóes também são ensaios, são falíveis. As regras para o sucesso do fazer são necessárias, mas não são um cálculo lógico, são algoritmos.

A retomada da Retórica considera que a arte de persuadir implica reconhecer as razóes que sustentam as resistências dos auditórios, que são a expressão das boas razóes que as pessoas têm para manterem suas crenças, atitudes e valores, como 
mostrou Boudon (1990, 1995). As boas razões não estão para além ou aquém do humano, expressam o que as pessoas julgam razoável acreditar ou fazer, ainda que não possam ser ineditamente apreendidas por quem as observa ou com elas interage, podem ser apreendidas por meio da análise retórica.

Mazzotti (2006), Mazzotti e Oliveira (2000), propuseram que a análise retórica das teorias produzidas nas Ciências da Educaçáo permitiria um diálogo que eventualmente produziria uma interdisciplina, o que implica a determinaçáo do objeto comum, bem como dos meios de investigação. Caso se considere que o axioma modal é o objeto comum, cabendo a definição dos limites das açôes a cada uma das ciências particulares, então essa interdisciplina já existe, é a Retórica, em que se considera as situaçóes sociais limitadores do desejado pelo orador.

Neste registro a educação escolar é um gênero da retórica, em que os condicionamentos institucionais têm sido investigados pela Sociologia, Psicologia Social e Antropologia, bem como pela História. Estas ciências fornecem os meios para compreensão das condiçóes em que os atores sociais desenvolvem suas relaçóes, o ethos escolar, que póem limites para a realização das mudanças de valores, crenças e atitudes. Logo, estabelecem as limitaçóes do auditório e dos oradores em situação.

\section{CONCLUSÃO}

O problema da cientificidade a Pedagogia geralmente se sustenta em uma teoria do conhecimento que tem por modelo o que se realiza nas ciências formais: o estabelecimento de um sistema bem formado de enunciados a partir de axiomas. Por essa via, nenhuma teoria reconstrutiva pode reivindicar o estatuto de ciência, ainda que seus modelos sejam retirados de alguma estrutura formal para descrever e explicar os fenômenos. A pertinência do modelo não decorre de sua verdade formal, mas de uma negociação entre os cientistas 
sustentada em procedimentos considerados canônicos e que operam o silogismo modus tollens. Mais ainda, os modelos ou metáforas são substituídos se e quando não atendem as condiçôes de uso, o que se pretende fazer.

A Retórica é uma das ciências reconstrutivas constituída a partir do exame das técnicas espontaneamente utilizadas pelos oradores e tem por objeto o axioma modal que afirma a possibilidade de se modificar as crenças, valores e atitudes. Uma vez que a arte retórica e a de ensinar/educar, bem como demais técnicas produtivas intelectuais e afetivas sustentamse no mesmo axioma, então todas têm o mesmo objeto: os limites da ação afirmada pelo axioma modal, cuja ciência é a Retórica. Neste registro, a Pedagogia é um gênero da Retórica, no qual também se recorre aos procedimentos da analítica para organizar o que se ensina.

Porém a Pedagogia não é um gênero retórico reconhecido pelos clássicos, particularmente por Aristóteles para quem o ensino é uma exposição encadeada que náo considera as particularidades do auditório, provavelmente porque constituído de adultos razoavelmente instruídos. Essa organização do ensino foi caracterizada como "lógica" por seus opositores, os que têm sido reunidos sob os coletivos "escolanovismo" ou "progressivismo", os quais afirmam a necessidade de um modo de ensinar "psicológico". Os escolanovistas retomaram uma recomendação da Retórica: a ação do orador deve (imperativo) considerar o auditório. Considerar o auditório escolar implica conhecer as suas condiçôes psicológicas, cognitivas e afetivas. A Psicologia desenvolveu inúmeras pesquisas acerca dessas condições, assim como a Sociologia tratou de aspectos sociais que condicionam as instituiçóes escolares, e a Psicossociologia tem desenvolvido investigaçóes que procuram explicar as relaçóes inter e intra grupais que delimitam o fazer educativo.

Não cabe aqui uma exposição dessas pesquisas. Cabe, no entanto, sustentar que as pesquisas no âmbito do gênero retórico educação, têm tido por objeto implícito as negociaçóes 
de significados que envolve a relação entre o professor (orador ou ethos), os estudantes (auditórios, pathos) e as matérias de ensino (logos). Ao explicitar essas negociaçóes também se expóe o seu axioma modal, cujos limites expressam a sua finitude. E ao considerar a educação um gênero da arte retórica explicita-se as suas técnicas e seu uso no trabalho escolar. O que viabiliza a analise dos conhecimentos sistematizados ensinados nas escolas segundo as figuras de pensamento, suas formas lógicas e quase-lógicas, bem como as razóes que sustentam as preferências que determinam os programas de ensino, sempre situados. É, pois, um programa de pesquisa que se apóia no reconhecimento da relação de complementaridade entre as técnicas retóricas, nelas incluídas as da dialética, e as da lógica, ou da exposição encadeada de conhecimentos já produzidos. O que parece ser um caminho razoável para superar a dispersão epistemológica em que se encontram as Ciências da Educação.

\section{REFERÊNCIAS}

ALVES-MAZZOTTI, A. J.; GEWANDSZNAJDER, R. O Método nas Ciências Naturais e Sociais. Pesquisa Quantitativa e Qualitativa. São Paulo: Pioneira, 1998.

ANDERSON, A. R.; BELNAP, L. Entailment. The Logic of Relevance and Necessity. Princeton: Princeton University Press, 1975.

ARISTOTLE. Prior and Posterior Analytics. The Works of Aristotle. Chicago: Encyclopedia Britannica, 1977.

dia Britannica, 1977.

. Topics. The Works of Aristotle. Chicago: Encyclope-

BAIN, A. La science de l'éducation. Paris: Alcan, 1885, 5a edição (www.bnf.fr N5667238_PDF_1_!DN_1.pdf).

BERTI, E. Aristóteles no século XX. S. Paulo: Loyola, 1991 (Aristotele nel novecento, 1992, Gius, Laterza \& Figli).

BERTO, F. There's something about Gödel. The complete guide to the incompleteness theorem. Oxford: John Wiley \& Sons, 2009.

BLACK, M. Models and Metaphors. Studies in Language and Philosophy. Itaca/London: Cornell University Press, 1972 (1962). scientifiques. Paris : Découvert/CNRS, 1989. 
CHARBONNEL, N. Les aventures de la métaphore. Strasbourg: Presses Universitaire de Strasbourg, 1991a.

. L'important c'est d'être propre. Strasbourg:

Presses Universitaire de Strasbourg, 1991b.

Philosophie du modèle. Strasbourg: Presses

Universitaire de Strasbourg, 1991.

. Métaphore et philosophie moderne.

CHARBONNEL, N. ; KLEIBER, G. La métaphore entre philosophie et rhétorique. Paris: Presses Universitaire de France (Linguistique Nouvelle), 1999.

BOUDON, R. L'art de si persuader des idées fausses, fragiles ou douteuses... Paris: Fayard, 1990.

. Le juste et le vrai. Paris: Fayard, 1993.

DA COSTA, N. C. A. Ensaio sobre os fundamentos da Lógica. S. Paulo: Hucitec e Editora da Universidade de São Paulo, 1980.

ENCICLOPÉDIA EINAUDI. Lisboa: Imprensa Nacional: Casa da Moeda, 1988. v. 10: Dialéctica.

GAGE, N.C. The paradigm wars and their aftermath: a "bistorical" sketch of research on teaching since 1989. Educational Researcher, v. 18, n.7, p 4-10, 1989.

HANKINSON, R. J. The Skeptics. London; New York. Routledge, 1995.

HOLTON, G. Thematic Origins of Scientific Thought. Kepler to Einstein. Cambridge: Harvard University Press. Revised Edition, 1998. . Ensayos sobre el pensamiento cientifico en la época de Einstein. Madrid: Alianza Editorial, 1982.

KUHN, T. S. The Structure of Scientific Revolutions. $3^{\text {a }}$ ed. Chicago: The University of Chicago Press, 1996.

MAZZOTTI, T. B. Ciências da educação em questão. Educação e Pesquisa, São Paulo, v. 32, n. 3, p. 539-550, set./dez. 2006

MAZZOTTI, T. B; OLIVEIRA, R. J. Ciência(s) da Educação. Rio de Janeiro: DP\&A, 2000.

QUINE, W. V. O. Méthodes de logique. Paris: Colin, 1972.

PERELMAN, C.; OLBRECHTS-TYTECA, L. Traité de l'argumentation. Bruxelles: Éditions de l'Université de Bruxelles, 2008 [1958]. 
PIAGET, J. Introducción a la epistemología genética. Trad. por M.T Cevasco e V. Fischman. Buenos Aires: Paidós, 1975. t.3: El pensamiento biológico, psicológico y sociológico.

PIAGET, J.; GARCIA, R. Vers une logique des significations. Genebra: Murionde, 1987 (Col. Science Nouvelle)

PICKERING, A. (Ed.). Science as practice and culture. Chicago: University of Chicago Press, 1992.

RUBIM, A. A. Como falar em Paradigmas na Educação. Revista brasileira de estudos pedagógicos, Brasília, v. 74, n.177, p. 425-443, 1993.

TARDY, M. De la pédagogie aux sciences de l'éducation. Encyclopédie Philosophique Universelle. L'Univers Philosophique. Paris: Presses Universitaire de France, p. 1282-1287, 1989.

WADDINGTON, C. H. Instrumental para o pensamento. Belo Horizonte: Editora Itatiaia; São Paulo: Editora da Universidade de São Paulo, 1979.

WOLFRAM, S. A New Kind of Science. Champaign, Illinois: Wolfram Media, 2002.

WOLFF, F. Trois techniques de vérité dans la Grèce classique: Aristotle et l'argumentation. Paris, CNRS, Hermes, v.15, n.1, 1995, p.41-72.

Data de recebimento: novembro de 2013

Data de aceite: junho de 2014 